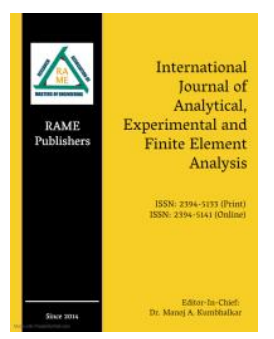

R. K. Halli ${ }^{1}$

Sidduhalli007@gmail.com

Omkar Dnyaneshwar Papal ${ }^{2}$ omkarpa999@gmail.com

Abhishek Laxman Shinde abhishekshinde19420@gmail.com

Saurabh Satish Rewadkar ${ }^{2}$ rewadkarsourabh9@gmail.com

Dhiraj Subhash Pawar dhirajpawar79551@gmail.com

${ }^{1}$ Assistant Professor and ${ }^{2}$ Student

Department of Mechanical

Engineering, JSPM Narhe technical Campus, Narhe, Pune, India

\title{
Accident Avoiding by Using Pneumatic Bumper
}

Abstract - A control system for pneumatic bumper activation and automated braking in automobiles is designed and built. The transmitter and receiver circuit, control unit, pneumatic bumper system and pneumatic brake system are all included in this project. The obstruction is detected by the IR sensor of the camera. The bumper activation system and pneumatic braking system are activated simultaneously if there is an obstruction in the path of the vehicle. In order to produce the man and vehicle, pneumatic bumper and braking systems are employed. A few automobile manufacturers currently utilise passive dampers positioned between the bumper and the vehicle's frame as a kind of shock absorption. It is possible to waste a large amount of energy through the compression of the damper. The residual force will be transmitted to the vehicle's chassis by means of this mechanism. Static damping coefficient of this system is typically quite high, making it unable to dissipate higher speed impact forces. To decrease the crash impact and transfer of the residual force, dampers were utilised in this project to give a dynamic damping coefficient. To create a notion for an accident-avoiding system that can fulfil the requirements of safe travel, the present study is an attempt. Embedded electrical sensor and mechanical elements are used in this idea, which is a bit different from other types of machines.

Keywords - FEA, pneumatic bumper, IR Sensor, damping, chassis.

\section{INTRODUCTION}

One of the most essential purposes of a vehicle's braking system is to properly stop the vehicle when it is moving. Vehicle damage, human harm, or even death, are nearly always the consequence of braking system failures. In the previous nine decades, the brake system in trucks and passenger automobiles has received a lot of attention. Every two seconds, a person dies in an automobile collision, according to Mr. Willie D. Jones in the IEEE Spectrum magazine (September 2001). It is important to

Research Paper - Peer Reviewed

Published online - 28 July 2021

(C) 2021 RAME Publishers

This is an open access article under the CC BY 4.0 International License https://creativecommons.org/licenses/by/4.0/

Cite this article - R. K. Halli, Omkar Dnyaneshwar Papal, Abhishek Laxman Shinde, Saurabh Satish Rewadkar, Dhiraj Subhash Pawar, "Accident Avoiding by Using Pneumatic Bumper", International Journal of Analytical, Experimental and Finite Element Analysis, RAME Publishers, vol. 8, issue 3, pp. 92-96, 2021.

https://doi.org/10.26706/ijaefea.3.8.20210708 automate vehicle driving controls. Various systems or procedures have been created for the safety of the driver, passengers, and vehicle, and improvements are continuously being made today.

Reverse cameras, parking sensors, and other technologies have been made in an attempt to decrease accidents while reversing a car, however they have not been able to halt accidents successfully. Due to the formation of a blind spot in the centre of the vehicle, parking sensors and rear view cameras are unable to be used effectively. Since the height of the vehicle is higher than that of other vehicles, the rear view cameras are unable to show the image properly and the vehicle will not brake automatically, increasing the risk of an accident. For the Mumbai Local Train, this idea is used to prevent accidents. The trains on the same track start buzzing when they are within 300 metres of each other and stop automatically when they are within 100 metres if the driver of one of the trains does not intervene. 
Depending on the kind of operation, the sensor's range can be expanded. They have a range of 1 to $1.5 \mathrm{~m}$, as we're dealing with infrared sensors. Only heavy-duty vehicles are eligible for the programme. Our best bet is to employ ultrasonic sensors, which have a range of $5 \mathrm{~m}$ to several hundred metres (as used in Mumbai Local).

- This method is applicable to all sorts of light vehicles, including automobiles, rickshaws, and tempos.

- System capable of increasing the safety of vehicles before an accident occurs.

- System plays an essential role in preventing traffic accidents and saving lives of those involved.

- Use exterior vehicle safety to reduce the number of passenger injuries.

- Internal safety measures such as airbags can be reduced.

In the realm of mechatronics and automation, numerous methods have been created simply to decrease the amount of time and human error. Mechatronics is included in the automatic braking system. An alert system is in place to keep the car at a safe distance from other vehicles. Alarm is triggered when the car comes too close to the item. This functionality, however, has a number of flaws and is prone to mistake. The same sensor system was used, but with the addition of an automatic braking mechanism that prevents the car from moving backwards. Trucks, buses and other vehicles using pneumatic braking systems are at risk of accidents when reversing. For this aim, we have built a model consisting of a pneumatic cylinder, a solenoid valve, infrared sensors, and a control unit [1].

The air brake system is used to halt or slow down a vehicle. The response time of the complete system plays a major role in the effectiveness of the brakes. Design the brakes so that the response time meets vehicle safety standards. A comprehensive analysis of the various braking system components is presented in this article, starting with the actuating valves, the control valve, the actuator and the foundation brakes. It has proven possible to forecast the response time for a typical $4 \times 2$ heavy commercial truck. A research comparing the transient torque generated by the present drum brake with an equivalent disc brake model was also carried out. Bond graph method and lumped system were used to model the arrangement.

An automobile's brake system is the principal safety system. Drivers should be able to stop their vehicles in the shortest feasible distance with the least amount of effort, while maintaining controllability. This study examines the experimental performance of the air brake system's combination valve. There are several factors that impact valve properties, and the work focuses on those parameters. The properties of valves under these conditions are investigated experimentally and evaluated [3].

A train's pneumatic brakes are an integral aspect of the train's safety system, and are thus important. Modeling may be used to efficiently design such systems, from requirement definition to HIL testing, as illustrated in this work. Along with the system level model, the valves modelling is presented. Further, a model of the wheel-rail interface was built to examine the wheel-slip prevention mechanism. When compared to measurements, the Modelica model has been validated by comparing it to measurements under different circumstances of contact. In addition, the model is completely parametric and may be used to test for varied levels of adhesion. It is then exported as c-code and integrated into an HIL system to provide an efficient test platform for the electronic Brake Control Unit [4].

The life of a regular guy nowadays is a fast-paced, stressful, and frantic one. In India, 14 lives are lost per hour due to traffic accidents, according to current data. Almost all highways in Germany, with the exception of the Autobahn, have speed restrictions that are set by law. It's also difficult for the motorist to continually be on the lookout for speed restriction signs and to change his speed in response to those indicators. An over speed indication gadget is utilised in this project to inform the motorist if they are going above the speed limit. Governing mechanism is provided to detect over-speed. As a result, a solenoid-operated pneumatic braking system is installed to maintain vehicle speed and prevent accidents. As long as your automobile has an over speed indication, you can be 
assured that you won't be ticketed for speeding, and that you won't be involved in an accident due to speeding [5].

An attempt has been made in this initiative to reduce such incidents in the Indian road transport situation. An signal of high speed is presented, and automated braking is done by shutting off the fuel supply to an engine when its setup speed is surpassed, according to our project design. A solenoid valve and an operational amplifier circuit employing LM324IC are utilised in our project [5].

\section{Analytical DESIGN}

With the AUTOCAD programme, a 3D model of the prototype was generated. In this case, the proportions are different from those utilised in the real prototype. Figure 1 shows a screen picture of a cad model that has been generated..

\section{A. Calculation of Pneumatic Cylinder Dimensions}

Assumptions: - Maximum Force acting on bumper is assumed to be $90 \mathrm{~N}$

Considering factor of safety as 1.25 ,

We design bumper for

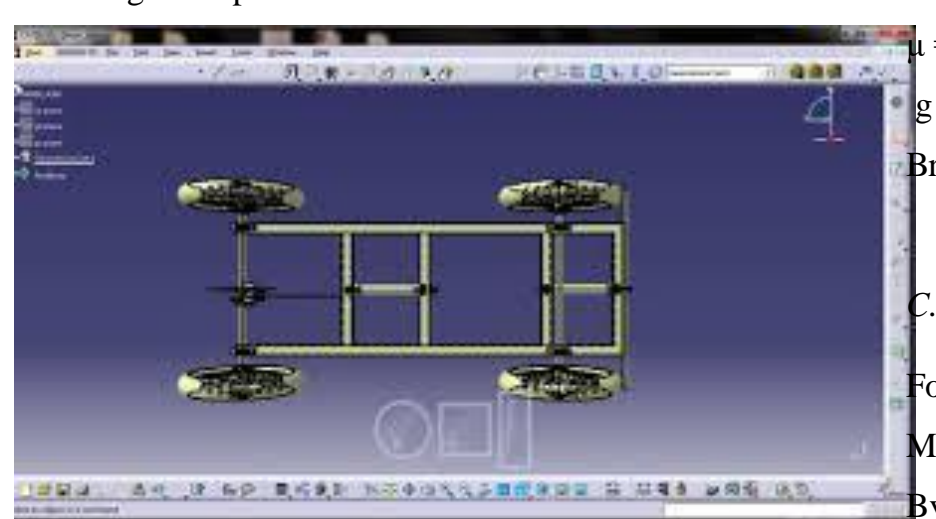

Figure 1.3D model

$90 \times 1.25=112.5 \mathrm{~N}$ force

Also, pressure used is $4 \mathrm{bar}=0.4 \mathrm{~N} / \mathrm{mm} 2$

For Bumper:

For Out-Stroke

$$
\begin{aligned}
& \mathrm{F} \mathrm{o} / \mathrm{s}=\mathrm{P} \times \mathrm{A} \\
& 112.5=0.4 \times \pi / 4\left(\mathrm{D}^{2}\right)
\end{aligned}
$$

So, $\mathrm{D}=18.92 \mathrm{~mm}$

Selecting standard value of $20 \mathrm{~mm}$ bore diameter

We calculate inner diameter.
Assuming In-stroke force to be equal to outstroke force, we assume in stroke force to be $90 \mathrm{~N}$.

For factor of safety of 1.25 , in stroke force is $112.5 \mathrm{~N}$

For in-stroke,

Piston rod area $=\pi / 4 \times \mathrm{d}^{2}$

Effective area $=\pi / 4 \times\left(D^{2}-d^{2}\right)$

$$
=0.7854 \times\left(20^{2}-\mathrm{d} 2\right) \mathrm{mm} 2
$$

So,

$\mathrm{F}_{\mathrm{i} / \mathrm{s}}=0.4 \times 0.7854 \times\left(20^{2}-\mathrm{d}^{2}\right)$

On solving, we get $\mathrm{d}=6.47 \mathrm{~mm}$

Hence, selecting from standard values, inner diameter is $8 \mathrm{~mm}$.

So, for both the double acting pneumatic cylinders, we increase the stroke length of cylinder used for extending the bumper [6].

So, for piston stroke of $90 \mathrm{~mm}$ is suitable.

\section{B. Calculation Of Braking Distance}

Braking distance, $\mathrm{Db}=[\mathrm{v} 2 /(2 \times \mu \times \mathrm{g})] \mathrm{m}$ Where,

$\mathrm{V}=$ velocity before applying brakes (App $10 \mathrm{~km} / \mathrm{hr}=2.78 \mathrm{~m} / \mathrm{s})$ $=$ coefficient of friction $=0.7$ (for dry surface) $\mathrm{g}=$ acceleration due to gravity $\left(9.81 \mathrm{~m} / \mathrm{sec}^{2}\right)$ Braking distance, $\mathrm{D}_{\mathrm{b}}=[2.78 /(2 \times 0.7 \times 9.81)]$

$$
=0.5618 \mathrm{~m}
$$

\section{Impact Force Calculation}

Force, $F=$ mass $(\mathrm{m}) \times$ acceleration $(\mathrm{a})$

Mass of the vehicle $m=10 \mathrm{~kg}$

By motion Equation, 2as $=v^{2}-u^{2}$

Where,

$\mathrm{v}=$ Final velocity $=2.78 \mathrm{~m} / \mathrm{s}$

$\mathrm{a}=$ acceleration,

$\mathrm{s}=$ braking distance $\left(\mathrm{D}_{\mathrm{b}}=0.5618 \mathrm{~m}\right)$

$\mathrm{u}=$ Initial velocity $=0$

$2 \times \mathrm{a} \times 0.5618=2.78^{2}-0$

$$
\mathrm{a}=6.78 \mathrm{~m} / \mathrm{s} 2
$$

Force, $\mathrm{F}=\mathrm{m} \times \mathrm{a}=10 \times(6.87)=68.7 \mathrm{~N}$

The Final impacting force value $\mathrm{F}=68.7 \mathrm{~N}$ 


\section{FE ANALYSIS}

FEM is a numerical mathematic method used in FEA. Mechanics, as well as a number of other disciplines, rely heavily on this process. One of the major ideas utilized in developing simulation software is likewise this principle. This allows engineers to minimize the number of physical prototypes and perform virtual trials on their ideas, thereby reducing the number of prototypes [7].

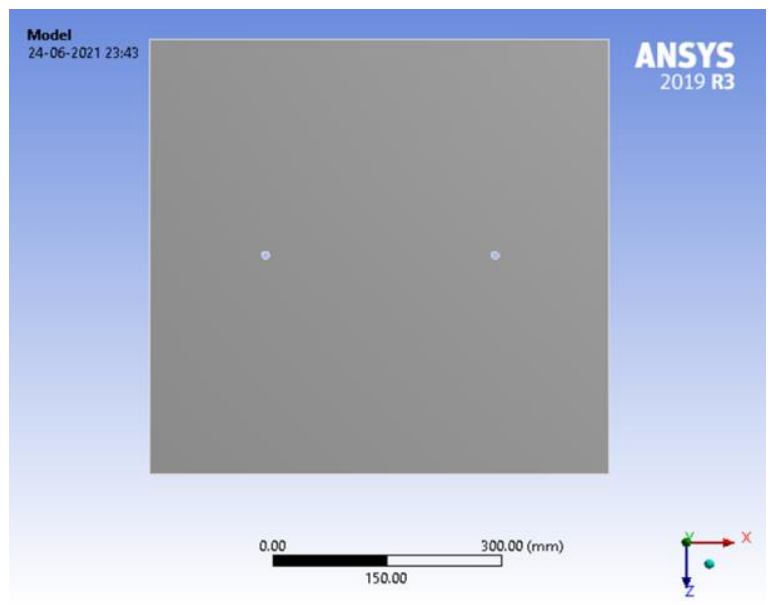

Figure 2. Geometry

An object's continuous geometric space is broken down into thousands or more forms in order to accurately characterise its physical shape, a process known as meshing. An accurate 3D CAD model requires a mesh that is as detailed as possible. This mesh allows for high-fidelity simulations.

- Element Size: $5.0 \mathrm{~mm}$

- Element type: Tetrahedral

- Nodes: 639806

- Elements: 288213

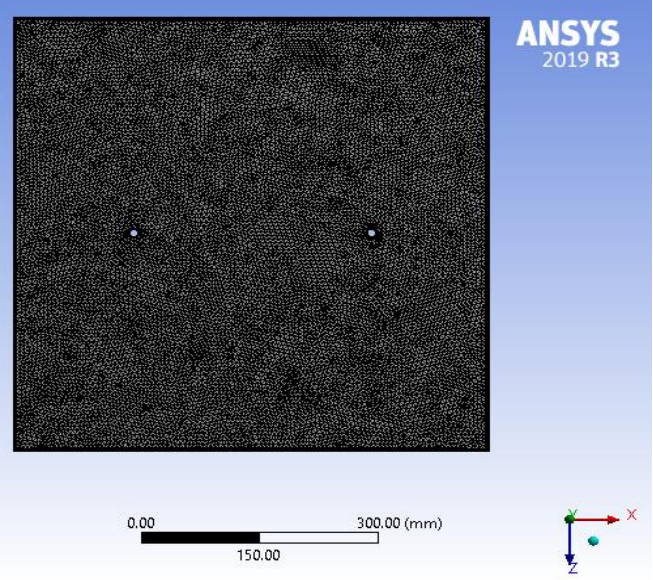

Figre 3. Meshing

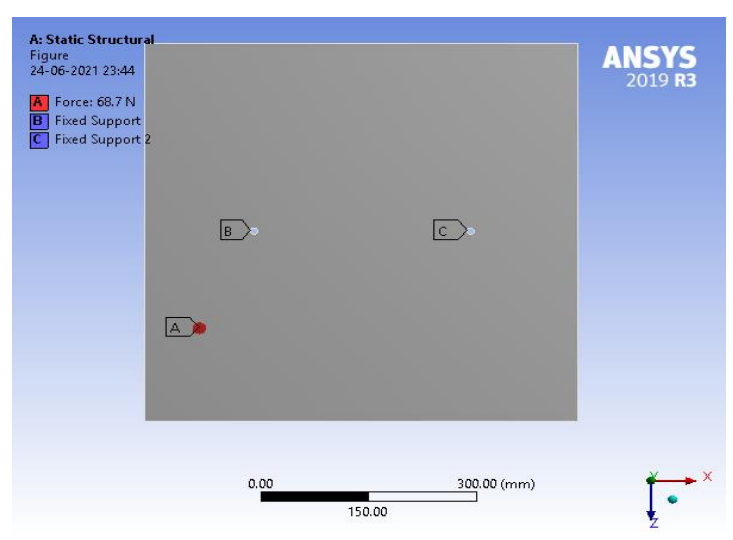

Figure 4. load apply

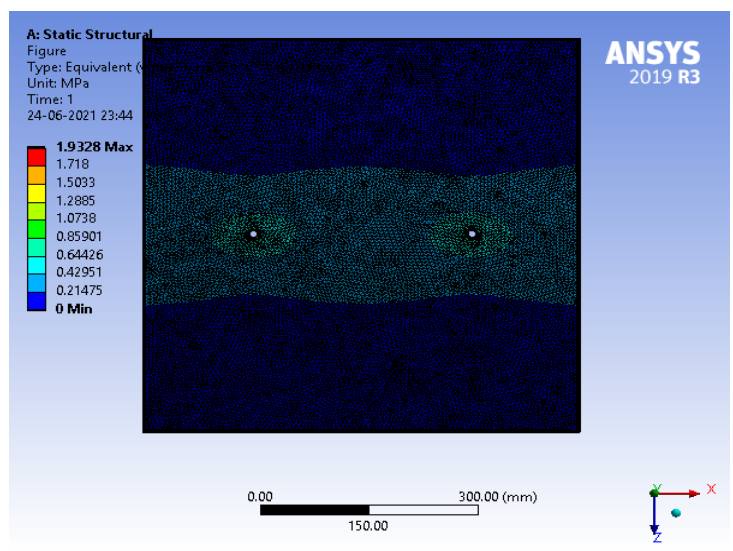

Figure 5. Equivalent Stress

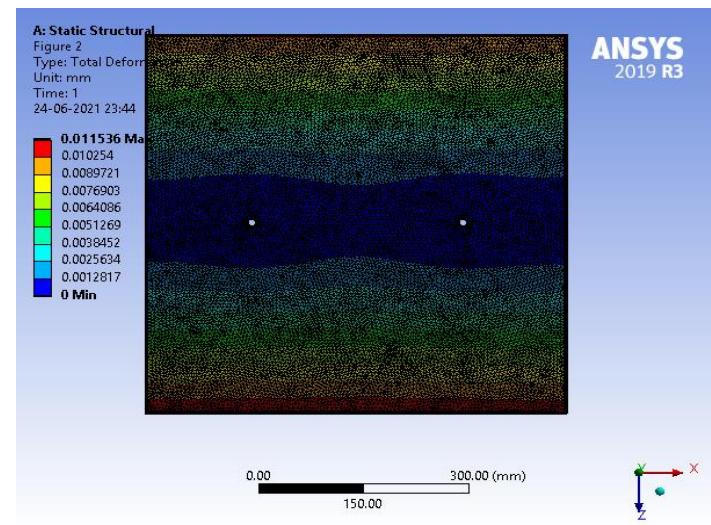

Figure 6. Total deformation

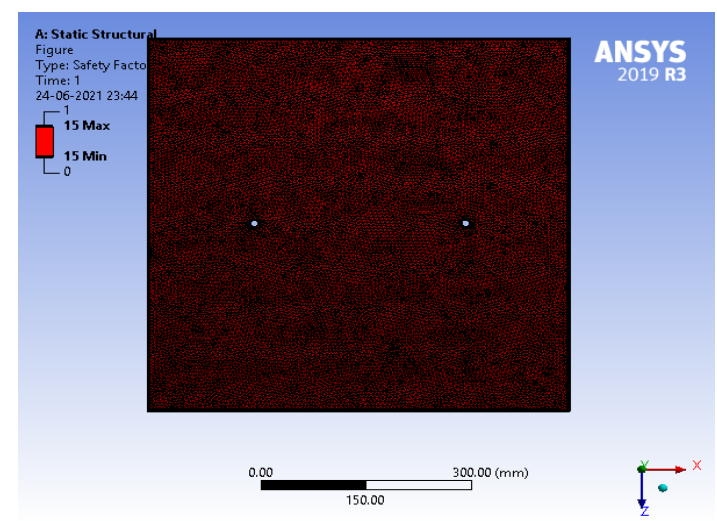

Figure 7. factor of safety 


\section{CONCLUSION}

Bumper is successfully modelled in modelling software CATIA V5R18. This model is analysed statically and then finite element analysis on impact using Ansys 19 R3 successfully. Maximum von misses stress is obtained is 1.9328. Factor of safety obtained as 15 and hence design is safe.

\section{REFERENCES}

[1] S. Suresh, T. Prashanth, B. Sahaya Joba, R. Tamilkumaran, R. Venkatesh , "Design and Analysis of Intelligence Braking System", International Journal of Engineering Research \& Technology (IJERT), volume 5, issue 7, 2017.

[2] Srinivasa Chari.V1, Dr.venkatesh P.R2, Dr.Prasanna Rao N.S3, Adil Ahmed S, "Automatic Pneumatic Bumper And Break Actuation Before Collision”, International Research Journal of Engineering and Technology (IRJET), Volume: 02 Issue: 04, July-2015.
[3] Harshal Rahate, "Experimental Work on Automatic Pneumatic Bumper", International Journal for Research in Applied Science \& Engineering Technology (IJRASET), Volume 6 Issue I, January 2018.

[4] Nivesh Thepade, Lakhan Thombare, Pritish Varude, Ashish Umbarkar, "Intelligent Braking System with Automatic Pneumatic Bumper", International Journal for Scientific Research \& Development, Vol. 4, Issue 04, 2016.

[5] Ashish Kumar, Rajat Gethe, Sattyendra Pethe Patil, Akshay Waychal, "Solar Power Tiller", International Journal of Scientific \& Engineering Research, Volume 9, Issue 10, October-2018.

[6] Robert C. Juvinall and Kurt M Marshek, "Fundamentals of Machine Components Design" 3rd edition, Wiley India Edition.

[7] Engineering \& System Integration, RAIT, FEM Analysis, https://rait88.com/engineering-system-integrationspecialised-department/?lang=en 